\title{
Die relevansie van die prediking vir tussenmenslike verhoudings in Suid-Afrika
}

Prof. J. H. van Wyk

\section{INLEIDING}

Indien ons die uitspraak verneem dat ten minste $77 \%$ van die SuidAfrikaanse bevolking hulle as Christene beskou, skep dit groot verwagtinge dat die prediking van die evangelie van Christus inderdaad van groot invloed kan wees. Indien ons hier byvoeg dat baie Christene in die geleentheid is om (sê) oor 'n periode van vyftig jaar (20-70 jaar) sowat 5000 preke te kan hoor (teen honderd per jaar), dan styg ons verwagtinge nog meer. Daarom is dit 'n baie pynlike bevinding om te moet hoor dat ondersoeke daarop dui dat die effek van die prediking soms baie gering is en dat dit min verandering teweegbring (Jonker, 1976 : $85-86$ ).

Tog sou ek die stelling wou verdedig dat die prediking inderdaad relevant vir tussenmenslike verhoudinge is en wel omdat hierdie relevansie ten nouste saamhang met die wese van die prediking. Daarom is dit belangrik dat ons vervolgens aandag bestee aan die vraag wat prediking inderdaad ís.

\section{PREDIKING IS SKRIFPREDIKING}

Prediking is niks anders en kan niks anders wees as bediening van die Woord van God (vgl 1 Kor $2: 6 \mathrm{ev}, 1$ Tess $2: 13$ ) en is nie 'n interessante vertelling van menslike ervaringe, insigte en wyshede nie. God moet deur die prediker aan die woord kom (1 Pet $4: 11$ ). Slegs as prediking verkondiging van die Woord van God is, kan dit werklik gesagvol tot die hoorders kom.

Geen wonder ook dat die Bybel vol is van mededelinge in verband met die betekenis van die Woord van God. Die Woord is ' $n$ lig op die pad ( Ps $119: 105)$, dus ook op die pad van tussenmenslike verhoudinge. Die Woord, en in besonder ook die Ou Testament, het groot waarde om 'n regte lewenswyse te kweek sodat iemand volkome toegerus sal wees vir élke goeie werk - dus ook vir elke goeie werk in tussenmenslike verhoudinge.

Die Woord van die Here belig dus die volle lewe en geen enkele terrein of faset van die lewe kan aan hierdie beligting en deurligting onttrek word nie. Wie hierdie volle beligting ook maar enigsins wil afgrens, versmal en vermink die Woord.

In hierdie verband hoor ons nogal dikwels die onderskeiding dat 'n predikant oor die politiek mag preek maar nie oor die partypolitiek nie. Dit is egter 'n groot vraag of hierdie onderskeiding volkome opgaan.

* Voordrag voor Gespreksgroep Kerk/Lniversiteit aan die Randse Afrikaanse L'niversiteit op 30 . Maart 1987 
Indien 'n prediker nie oor die partypolitiek mag preek nie, dan ontstaan die vraag of daar nie tog weer 'n stukkie van die lewe onttrek word aan die beligting van die Woord nie. Bowendien het niemand beswaar om teen die partypolitiek van bv. die kommunisme te preek nie en waarom dan nie ook wanneer die politiek nader aan huis kom nie? Politiek en partypolitiek handel immers vir 'n baie groot deel oor tussenmenslike verhoudinge en die heel grootste woord oor menslike verhoudinge kom tog van niemand minder nie as Jesus Christus. Ek bedoel sy beroemde uitspraak in Matt $7: 12$ : "Alles wat julle wil hé dat die mense aan julle moet doen, moet julle ook aan hulle doen". En om te illustreer hoe ek vir iemand anders 'n naaste kan wees, het Jesus die bekende gelykenis van die barmhartige Samaritaan vertel (Luk 10:25-37).

Omdat prediking verkondiging van die Woord van Gód is, en omdat God se Woord gerig is op die heil en harmonie van mense (waarvan die keersy onheil is indien die Woord nie gehoorsaam word nie), daarom hét dit besondere betekenis vir tussenmenslike verhoudinge, veral ook vir die gespanne verhoudinge in Suid-Afrika.

\section{PREDIKING IS EVANGELIEPREDIKING}

As ons sê dat prediking niks anders is as evangelieprediking nie, dan bedoel ons daarmee dat die prediker 'n goeie boodskap bring van verlossing deur Jesus Christus, ons Here, en dat hy nie allerlei interessante waarhede verkondig nie (Jonker, 1976: 63). Dit gaan in die prediking om wat God in Christus deur sy Gees in hierdie wêreld doen.

In die evangelieprediking gaan dit om Christus as Verlosser, as volkome Verlosser. Dit gaan dus nie om swart of wit politieke ideologiee of programme van verlossing nie. Evangelieprediking relativeer alle menslike gedagtes, planne en pogings.

Evangelieprediking beklemtoon ook dat Christus totale Verlosser is. Hy is dus oneindig meer as net n 'sieleredder'. Hy verlos ons mét alles ván alles. Hy verlos ons van álle bose magte (Kol 2: 15; Velema 1972:28). Sy verlossing omvat ons gees en liggaam (Velema 1987:16), dit raak ons persoonlike sonde en onregverdige strukture. Reeds in die Ou Testament blyk dat die verlossing wat God vir sy volk Israel bewerk het 'n volkome verlossing is: die volk word immers verlos uit die afgodery van Egipte (noem dit ' $n$ 'godsdienstige verlossing') en die volk word verlos van die slawerny van Egipte (noem dit 'n 'politieke verlossing'). As God sy volk verlos, sowel in die OT as in die NT, dan bewerk Hy inderdaad 'n volkome verlossing.

Maar Christus is meer as Verlosser, Hy het ook iets anders kom doen: Hy is ook Versoener. Hy versoen mense met God (2 Kor $5: 18-19$ ) maar die implikasie hiervan is dat mense ook met mekaar versoen word. Die kerk is tog niks anders as 'n gemeenskap van versoendes en Christene word ook opgeroep om in die samelewing 'n gesindheid van versoening en vrede te openbaar (Rom 12:18).

Dit kan dus nie anders nie as dat die prediking as evangelieprediking noodwendig tussenmenslike verhoudinge moet raak en moet verander.

\section{PREDIKING IS VERBONDSPREDIKING}

Wanneer ons die prediking as verbondspredikıng tipeer, dan word daarmee veronderstel dat die verbond 'n sentrale tema in die Skrif is. 
Verbond beteken, kort gesê, dat God in 'n besonder noue verbintenis tot sy volk staan. In die verbond kom ter sprake dat God gee, dat God belowe en dat God vra. Hy gee verlossing, Hy belowe 'n nuwe wêreld, maar Hy vra ook gehoorsaamheid en bekering - bekering dan in sy volle betekenis van denkverandering en daadverandering (Jonker. $1976: 88$ ).

In die verbondsprediking word die volk van God, die kerk, opgebou en toegerus ( $\mathrm{Ef} 4: 11 \mathrm{ev}$ ). Hierdie toerusting hou onder andere in dat die gelowiges Christelike volwassenheid aan die dag sal lê, ook in die politiek. Dit is my diepste oortuiging dat talle predikante so huiwerig is om oor die politiek te preek omdat die lidmate geestelik te onvolwasse is om hierdie soort prediking te waardeer. Gevolglik word lidmate deur hierdie faset van prediking gou 'ontstig' - 'n foutiewe woordjie wat nagenoeg die einde van alle profetiese getuienis beteken. Indien ons egter objektief na die prediking van die OTe profete en ook na die prediking van Christus kyk, dan blyk dit duidelik dat hulle dikwels die hoorders baie 'ontstig' het en wel omdat die hoorders telkens geweier het om te buig voor die Woord van die lewende God en omdat die hoorders vasgehou het aan hulle eie woorde en tradisies.

Dit is egter baie gevaarlik vir die prediker indien hy die kriterium vir sy prediking verplaas van die Woord van God na die hoorder of die openbare mening (Muller, 1985: 142, 147, 150). Dan bring hy immers nie meer die Woord van God nie maar laat hy hom lei en beheers deur buiteSkriftuurlike invloede soos bv die tydsgees (Jonker, $1976: 110$ ).

Verbondsprediking beteken dat die prediker die lidmate moet toerus om die wil van God te ken en te doen (Kol $1: 9$ ).

Verbondsprediking beteken nie dat die lidmate aan die slaap gesus word op pad hemel toe nie. Voortdurend moet daar gewaak word teen 'n valse gerustheid en 'n verbondsoutomatisme (De Klerk, 1964 . 40-44, Postma, 1980). Dit word beweer dat tydens die Tweede Wêreldoorlog toe Hitler die wêreld oorrompel en met sy terreurdade voortgegaan het, talle Duitse predikante as teks by die prediking dikwels Rom 8 : 31 gebruik het: "As God vir ons is, wie kan teen ons wees?" Nee, verbondsprediking is nie dieselfde as valse-gerustheid-prediking nie. Ook hier kan ons weer by die OTe profete leer, veral die profete Jeremia en Amos. Hulle prediking was besonder fel teen elke sosiale onreg, teen elke onmenslike handeling, teen elke verontregting en verknegting, of om dit modern te sê: teen elke diskriminasie en dominasie.

Juis omdat gelowiges in 'n verbondsverhouding tot die lewende God staan, kan die verbondsprediking sowel vertroos as opskerp, sowel die Goddelike verlossing en beloftes onderstreep as oproep tot gehoorsaamheid aan die wil van die Here, ook en veral ten opsigte van tussenmenslike verhoudinge.

\section{PREDIKING IS KONINKRYKSPREDIKING}

Die koninkryk van God is in 'n bepaalde sin dié groot tema van die ganse Skrif en daarom word daar nie verniet nie in die NT dikwels gepraat van die "evangelie van die koninkryk". Wie die evangelie van die koninkryk verkondig, verkondig God se geseende heerskappy oor alle dinge, verkondig dat Jesus Christus Koning oor alles is. 
Dit val dadelik op dat die prediking van die koninkryk sentraal staan in albei uitsendings van die dissipels deur Christus. In die uitsending van die twaalf na Israel moet hulle gaan verkondig dat die koninkryk van die hemel naby gekom het (Matt $10: 7$ ). Dit moes die dissipels vanuit die staanspoor duidelik weet dat die koninkryk van God prioriteit geniet en nie enige ander menslike koninkryk nie, nie die koninkryk van Rome nie en ook nie die koninkryk van Israel nie. Matteus was 'n tollenaar, dus pro-Romeins, iemand wat 'n imperialistiese politiek gevolg het, 'n man van die status quo. Simon die Seloot was weer anti-Romeins, 'n rewolusionêr, 'n man van die politiek van verandering (en miskien Judas Iskariot ook). Maar albei hierdie dissipels, en al die ander, sou moes leer dat die politiek van die koninkryk van God voorop gaan en alle menslike politiek relativeer. Die beginsels van ' $n$ politiek van die koninkryk is immers vryheid, vrede, blydskap en geregtigheid in die Heilige Gees (Rom $14: 17$ ).

In die tweede uitsending van die dissipels, hierdie keer na die hele wêreld (Matt 28 : 19-20), blyk hoe sentraal die koninkryk van God is. Die prediking geskied vanuit die vaste veronderstelling dat alle mag in hemel en op aarde aan Christus behoort. Daarom kan die dissipels heil verkondig, d.w.s. dissipels van Christus maak, en daarna moet hulle hierdie dissipels leer wat heiliging van die lewe is, d.w.s. mense leer om alles te onderhou wat Christus beveel het (vgl. Velema. $1972: 34$; Velema. $1987: 9 \mathrm{ev}$ ). Hulle moet dus ook die mense leer dat Christus beveel het dat Christene aan ander mense moet doen wat hulle graag aan hulleself gedoen wil hê; hulle moet ander leer dat Christus geleer het om ander mense soos jouself lief te hê. Hulle moet selfs ander leer dat Christus beveel het om vyande lief te hê. En watter belangriker woorde kan daar op aarde oor tussenmenslike verhoudinge gevind word as juis hierdie besondere woorde van Christus oor liefde tot die medemens?

In die gevestigde kerke bestaan daar 'n neiging by predikers om net die heil in Christus te verkonding en om van die heiliging van die totale lewe te vergeet, maar dan word twee sake wat wesentlik bymekaar hoort, nl. heil en heihging, vanmekaar losgemaak. Aan die ander kant is daar die gevaar, wat dikwels in die politieke teologie na vore kom, om heil en heiliging te vermeng en te maak asof alles net heiliging is. In beide gevalle word in uiterstes verval en lei die prediking groot skade. Predikers moet nie stilstaan by die eerste dinge wat aangaande Christus verkondig word nie maar moet verder gaan na die volle inhoud van die boodskap (Heb $6: 1$ ). Maar predikers mag ook nie die indruk probeer skep dat mense deur 'n goeie en voorbeeldige lewe van naasteliefde hulle daardeur self kan red nie.

Ons het genoem dat die koninkryk van God met alles op aarde te maak het en dat daarom die prédiking van die koninkryk ook met alles te maak het (Velema, 1972:25, 27; Jonker, 1976:124). In die prediking sal dus noodwendig aan politieke en maatskaplike sake aandag gegee moet word (Vorster, 1981 : 63; Van Wyk, 1984 : 199 - 205). As die koningskap van Christus oor alles gaan en as die lig van die Woord oor alles skyn, dan sal daar in die prediking aandag gegee moet word aan sake soos oorlog en vrede, besoedeling en bewaring van die natuur, gebruik en misbruik van die natuurlike hulpbronne, behandeling en mishandeling van mense ens. Die koms van die koninkryk van God na hierdie wêreld beteken immers 
niks anders as dat God besig is met sy groot regmaakproses van hierdie wêreld. Soos suurdeeg werk die koninkryk, en die beginsels van die koninkryk, in op elke faset van die lewe.

Laat ek een besondere kenmerk van die koninkryk, wat in die Bybel so 'n belangrike plek inneem, en vir tussenmenslike verhoudinge so deurslaggewend is, nader toelig. Ek verwys hier na die begrip geregtigheid. As die Bybel een woordjie moet uitsonder om die lewe op die nuwe aarde te omskryf, dan word juis die woord geregtigheid gebruik (2 Pet $3: 13$ ). En geregtigheid beteken niks anders nie as dat alles rég is: die mens se verhouding tot God is reg en die mens se verhouding tot sy medemens is reg; ons kan selfs sê dat die mens se verhouding tot die natuur ook reg sal wees. Alles is op die nuwe aarde rég. Alle onreg is weg. Vir tussenmenslike verhoudings is so 'n benadering bepalend; alle onreg tussen mense staan hierdeur veroordeel. Vandaar ook dat die Bybel kan sẽ dat vrede slegs dan moontlik is wanneer daar onder mense geregtigheid geskied (Jes $32: 17$, Ps $85: 11$ ).

Koninkryksprediking is dus eskatologiese prediking wat stippellyne trek vanuit hierdie aarde na die nuwe aarde, waarvan ons die koms kan verwag en selfs kan verhaas ( 2 Pet $3: 12$ ) - dalk deur ons prediking ( vgl. Matt $24: 14$ ) ?

Laat ons duidelik wees: die koninkryk van God wat ons verwag, is nie iets vaag of bloot toekomstig nie, nee, dit het aarde toe gekom met die koms van Jesus Christus en met die koms van die Gees van God, dit is hiér. En daarom moet dit só verkondig word. Elke goeie evangelieprediking en elke goeie koninkryksprediking is dus noodwendig ook goeie situasieprediking (Müller, 1985 : 143). Natuurlik moet ons onderskei tussen die evangelie wat ons bring en die situasie waarin die evangelie gebring word, maar die prediking mag nooit in tydloosheid verval nie (Jonker, $1976: 69,109$ ). Goeie prediking is elke keer 'n tydwoord, 'n woord, nee, 'n Woord op die regte tyd. Dit was juis 'n kenmerk van die valse profesie in die OT dat die valse profete so tydloos gepreek het, so oor waarhede gehandel het wat niemand geraak, aangespreek of selfs seergemaak het nie. Daarom is goeie prediking ook konkreet en op die man af en dus meer as blote 'beginseluitsprake' (vgl Runia, 1985:91).

\section{SLOTOPMERKINGS}

Aangesien bogenoemde kort uiteensetting maklik misverstaan kan word, wil ek graag ten slotte enkele opmerkings maak oor wat prediking nié behoort te wees nie.

\subsection{Prediking behoort nie politikistiese prediking te wees nie}

(Vgl. Bosch, $1979: 212$; Muller, 1985 : 143 - 146; Van der Walt, 1985b : 140; Velema, $1972: 11$ - 12.)

Met politikistiese (sommige praat van politieke) prediking bedoel ek dat die preek opgaan in 'n politieke toespraak. Op hierdie wyse word die evangelie verwater en verhorisontaliseer (Jonker sj : 148). Op hierdie wyse word ook die verbondsgedagte gedevalueer aangesien God dan met alle mense, gelowiges en ongelowiges, presies eenders sou handel (Velema, 1972:20) - 'n siening wat nogal in die politieke teologie veelvuldig voorkom. 
Prediking ór die politiek moet egter van politieke prediking onderskei word. 'n Preek wat nie van 'n politieke toespraak onderskei kan word nie, is nie meer prediking in die ware sin van die woord nie en ontbeer ook alle ware gesag. Hierdie waarskuwing geld vir swárt sowel as wit politieke prediking (Du Preez, 1979: Pretorius, Sept. 1977: Smit, 1982 : 13 ev: d'Assonville. 1976 : 95: Borchardt. $1975: 98.114$ ).

\subsection{Prediking behoort nie pietistiese prediking te wees nie}

(Vgl. Bosch, 1979 : 206, 207, 209: Müller, 1985 : 140 - 143.)

Met pietistiese of privatistiese prediking word bedoel dat die prediking opgaan in mistieke meditasie sonder raakpunte met die volle werklikheid. Op hierdie wyse word die evangelie egter versmal en moet lidmate die volle reikwydte daarvan ontbeer. Wat egter op hierdie standpunt nie altyd duidelik besef word nie is dat hierdie tipe prediking ook op 'n eie wyse politieke prediking is in soverre as wat dit die status-quo politiek stilswyend aanvaar en moontlik selfs ondersteun (vgl. Velema, 1972 : 7; Jonker, 1976 : 122). Die uitspraak "hou politiek uit die kerk" beteken dikwels niks anders as "hou jó politiek uit die kerk sodat ek mýne in kan hou"!

\subsection{Prediking behoort nie dogmatistiese prediking te wees nie (Vgl. Van der Walt, 1985a : 56 - 58: Bosch, $1979: 204)$}

In dogmatistiese prediking word oor 'ewige waarhede' gehandel sonder enige etiese toespitsing. Dit verwaarloos die konkrete en praktiese toepassing - 'n saak wat natuurlik nie sonder gevare is nie (vgl. Runia. Junie $1985: 98)$. So 'n prediking is egter sterk eensydig, omdat leer en lewe, dogmatiek en etiek in die Skrif altyd in die nouste verband ter sprake kom. Verantwoorde prediking moet noodwendig met beide komponente rekening hou.

S.P. van der Walt stel dit só: "In die prediking moet daar 'n groot, 'n baie groot verandering kom. Dit is moeilik om die verandering in woorde te bring, maar ek kan 'n poging waag deur te sê: ons prediking was in die verlede sterk dogmaties gekleur en dit moet nou ook sterk eties wees, sonder om die dogmatiese of leerstellige prys te gee" (Van der Walt. 1974 : 10; vgl. Smelik, $1967^{3}$ ).

\section{SLO'T}

Alles saamgevat meen ek dat goeie prediking inderdaad vir tussenmenslike verhoudinge van fundamentele betekenis is. Dat dit dikwels nie die geval in Suid-Afrika is nie, lê nie by die Woord wat gebring word nie. Veel eerder sal ons die fout moet soek by onvrymoedige predikers en opstandige hoorders. Die Woord is "lewend en kragtig" ( Heb 4:12) en kan alles verander, ook slegte tussenmenslike verhoudinge. Dit moet net vrymoedig verkondig en gehoorsaam aanvaar word. Suid-Afrika het in hierdie uur van krisis geen groter behoefte as juis dit nie.

\section{BRONNE}

Barkey Wolf. A G (red). 1959' Hoe vindt I dat er gepreekt moet worden? Zwolle: La Riviere \& Voorhoeve.

Borchardt, C F A. 1975. Die Afrikaanse Kerke en die Rebellie. 191415 (In Eybers, I H. Konig. A. Borchardt (red) Teologie en Vernuwing Pretoria: Unisa, 85 116) 


\section{In die Skriflig}

d'Assonville. V E. 1976. Die dwaasheid om te preek. Johannesburg: De Jong.

De Klerk. W J. 1964. Wending?: Vernuwingsgesprekke oor die Gereformeerde kerkpraktyk Potchefstroom : Pro Rege Pers

Dijk. K. 1952. De Dienst der kerk. Kampen - J H Kok (veral 79 - 114).

Du Preez. J. 1979. 'n Beoordeling van wit en swart "volksprediking" in die Ou Testament (In Odendaal, D H (eindred). Die Ou Testament Vandag. Kaapstad: NG KerkUitgewers. 107 - 118).

Hoekstra. T. 1926. Gereformeerde Homiletiek. Wageningen: Zomer \& Keuning.

Jonker, $H$. sj. Actuele prediking. Nijkerk: G F Callenbach.

Jonker. W D. 1976. Die Woord as Opdrag: Gedagtes oor die prediking. Pretoria: NG Kerkboekhandel.

Marais. B J. Boshoff, C W H (red). 1972. Rondom die Prediking (Erebundel aan prof dr H D A du Toit). Pretoria: NG Kerkboekhandel.

Muller, B V A. 1985. Die sosiopolitieke dimensie van koninkryksprediking. (In Louw, D J (red). Op die breuklyn. Kaapstad: NG Kerk-Uitgewers. 139 - 152).

Pretorius, H L. Sept 1977. Wit/swart bevrydingsteologie in Suid-Afrika. Ned Geref Teologiese Tydskrif, 18(4) : $343-352$.

Postma. D. 1980. Prediking en Verbond. Potchefstroom: C J B.

Runia. K. 1981. Heeft preken nog zin? Kampen: J H Kok.

Runia. K. Junie 1985 Prediking en Politiek-Sociale Vragen Theologia Reformata, 28(2) : $85-100$.

Runia, K. 1985. Het Hoge Woord in Lage Landen. Kampen: J H Kok.

Smelik. E L. $1967^{3}$. De ethiek in die verkondiging. Moraal zonder moralisme. Nijkerk: G F Callenbach.

Smit, J H. 1982. Swart Teologie. Wit Teologie en Hermeneutiese Beginsels. Bloemfontein: UOVS

Van der Walt, J J (red). 1985a. "God aan die Woord". Potchefstroom: Dept Diakoniologie $\mathrm{PU}$ vir $\mathrm{CHO}$

Van der Walt. J J. 1985b. Prediking en Politiek (In Van Wyk, J H en Vorster, J M (red). Altyd Reformeer. Braamfontein: De Jong, 133 - 141).

Van der Walt, S P. 20 Feb 1974. Ons veranderende wẽreld, Die Kerkblad, 76(2238).

Van Wyk, J H. 1984. Etiek van Vrede. Stellenbosch: Cabo $(199-205)$.

Velema. W H. 1972. Politieke prediking. Kampen: J H Kok.

Velema. W H. 1987. Het spreken en het preken van de kerk. Kampen: J H Kok. 